\title{
Optimizing the spatial organization of rural settlements based on life quality
}

\author{
TANG Chengli ${ }^{1}$, HE Yanhua ${ }^{1}$, ZHOU Guohua ${ }^{1,2}$, ZENG Shanshan ${ }^{3}$, XIAO Luyao ${ }^{1}$ \\ 1. College of Resource and Environment Science, Hunan Normal University, Changsha 410081, China; \\ 2. Hunan Key Laboratory of Geospatial Big Data Mining and Application, Hunan Normal University, Changsha \\ 410081, China; \\ 3. Urban and Rural Planning Bureau of Wangcheng District, Changsha 410200, China
}

\begin{abstract}
Optimizing rural settlements is an important measure to cope with rural decline, and improve the quality of rural life and attractions. This study introduces the "life quality theory". Based on the mechanisms governing the interactions between rural settlement space and life quality, this study examines how to optimize the spatial organization of rural settlements. Three aspects are evaluated - the integration of rural settlement spatial functions, optimization of spatial structure, and regulation of spatial scale - with the objective of building an optimization mode and framework for the spatial organization of rural settlements with high life quality. Our results suggest the following: (1) The settlement is the spatial carrier of life quality, which is an essential settlement component, and these two aspects influence and improve each other. Therefore, reasonable rural settlement space is an important precondition for higher life quality. (2) The spatial function types of rural settlements can be divided into those that maintain livelihoods, develop industry, and upgrade life quality. Optimizing spatial organization of rural settlements based on life quality requires promoting the maintenance of livelihood, integration of industrial development, and implantation in quality improvement. (3) There are two important components of optimizing the spatial organization of rural settlements. One is promoting the organic concentration of living, agricultural, and industrial spaces, the reasonable distribution of social intercourse, recreational, and services spaces, and the organic balance of living, production, and ecological spaces, so as to reasonably optimize the combination of internal spatial types in settlements. The other is forming a functional structure level of a "comprehensive village-featured village" and building spatial organization settlement modes connected by rural roads by relocating and adjusting the function of villages. These changes would require the destruction of underdeveloped villages, retaining normal villages, enlarging important villages, and constructing new villages. (4) As an ideal mode for optimizing rural settlements space based on life quality, the Rural Road-Oriented Development Model (RROD model) should be built at a rational scale for unit settlement and distance between settlements, leading to a fully functional RROD system with rational structure, auxiliary facility, and well-organized distribution.
\end{abstract}

Received: 2017-09-15 Accepted: 2017-10-20

Foundation: National Natural Science Foundation of China, No.41471145; National Social Science Foundation of China, No.41201169; The Key Discipline of Hunan Province Geography Construction Project, No.2011001

Author: Tang Chengli (1964-), Professor, specialized in human geography and regional development. E-mail: tclxy68@163.com 
Keywords: rural settlement; life quality; spatial optimization; RROD model

\section{Introduction}

Rural settlements are residential areas in rural environments, where the population has settled based on the close relationship with agriculture, in both geography and function (Li and Chen, 1994; Zhao et al., 2006). As world urbanization processes have expanded, rural decline has been a global issue (Liu and Li, 2017), and rural settlement has become a popular topic for scholars and experts in relevant fields both internationally and domestically. International research on rural settlements has been progressing over a longer period of time, and suggests four stages - sprouting, preliminary development, development and revolution, and restructuring (Li and Zhang, 2012a); this systematic and rich research has addressed settlement patterns (Amarasinghe et al., 2005; Bański and Wesołowska, 2010), ecology (Gilman, 1991; McKenzie et al., 2011), and landscapes (Antrop, 2004; Górka, 2016; Montis et al., 2017). In recent years, as human geography has transformed socially and culturally, international research on rural settlement geography has focused on interdisciplinary research in sociology and history, extending to rural reconstruction (Hoggart and Paniagua, 2001a; 2001b; Nelson, 2001), rural-urban relationships (Hidding and Teunissen, 2002), and rural social problems (Anthopoulou et al., 2017; Flynn and Kay, 2017; Woods, 1997), i.e., research has become more diverse.

During the transformation from "rural China" to "urban China", rapid urbanization has resulted in rural transformation and development and spatial reconstruction in China (Long, 2013); rural China is entering a new development stage (Liu, 2007; Long et al., 2011). With the migration of urban and rural populations, and the restructuring of economic and social development factors, non-agriculture diversification has been a powerful impetus for rural development and has accelerated the destruction of the ecological environment and rapid loss of agricultural land. The depopulation and hollowing has resulted in the loss of "order" and "vitality" from rural society, accelerating the decline of rural culture, so equalizing urban and rural public services is facing severe challenges. Rural settlements, as the spatial carrier of rural economic and social development, are confronted with the problem of reconstruction. Understanding the optimal scale and spatial patterns of rural settlements (Li, 2013) and constructing rural settlement spaces that meet the needs of farmers' desires for production and living through reasonable spatial organization of rural settlement are key factors in rural settlements addressing "rural disease" (Liu, 2013). Furthermore, these are also key factors in gradually developing competitive and beautiful homes. These are important topics that need to be addressed urgently in the field of theoretical rural geography research and new construction practices.

Many scholars have conducted research on rural settlements since the 1990s (Guo and Wang, 1999; Hai and Li, 2013; Li Q L et al., 2012; Liu et al., 2011; Long et al., 2016; Ma et al., 2016; Tian, 2011; Zhang and Sheng, 2005; Zhou and Zhang, 2005; Zhu et al., 2016). In recent years, there has been a special focus on rural settlement transformations and spatial reconstruction ( $\mathrm{Li}$ and Zhang, 2012b; Long, 2014; Wang and Li, 2011; Yang et al., 2015; Zhang et al., 2016), the spatial evolution and influencing mechanisms of rural settlements (Feng and Chen, 2003; He et al., 2013; Huo et al., 2016; Li and Shi, 2008; Li X J et al., 2009; Luo and Li, 2011; Qiao et al., 2009; Zhou et al., 2013; Zhang et al., 2017), hollowing of 
rural settlements and renovation of village-hollowing (Chen et al., 2010; Hu et al., 2016; Liu et al., 2009; Liu et al., 2013; Long et al., 2009; Tan et al., 2017; Zhu X H et al., 2010), and rural human settlements and the protection of settlement landscapes (Fang and Liu, 2009; Hu et al., 2013; Li B et al., 2009; Li et al., 2014; Li et al., 2009; Liu, 2006; Wu, 2001; Zhou, 2009; Zeng et al., 2016). In general, the research on rural settlements space varies from simple to comprehensive, qualitative descriptions to quantitative analysis, and spatial analysis to humanistic social paradigms. Nevertheless, issues, including weakness in fundamental theory, dominate regional spatial research, which requires enhancing the multidisciplinary coherence analysis. In particular, there are insufficient data on the interactions between people, community subjects, and their settlement environment; residential demands; and potential improvements to life quality function.

This study is an attempt to elucidate the intrinsic connections between rural settlements and life quality based on three aspects: the integration of rural settlement spatial functions, optimization of spatial structure, and regulation of spatial scale. The ultimate goal is to build an optimization mode and framework of spatial organization for rural settlements with high quality of life. The results should enrich spatial structure theory in settlement geography and provide theoretical guidance for the development of rural settlement space optimization policy to meet National Strategic Needs.

\section{The relationship between rural settlement space and life quality}

\subsection{Life quality and its evaluation framework}

"Life quality" was first proposed in 1958 by the American economist John Kenneth Galbraith in The Affluent Society; he posited that "the life quality is comfortable and convenient degree of people's life and the enjoyment and pleasure of the spirit". In the 1970s, the American economist Walt Whitman Rostow further studied "life quality," and formally proposed and explicitly elaborated on a "life quality theory" (Rostow, 1971) in Politics and the Stages of Growth. The author argued that economic modernization in each country occurs in five basic stages of varying length: traditional society, preconditions for take-off, take-off, drive to maturity, and high mass consumption, the fifth stage reflecting a characteristic quantitative consumption. Subsequently, citizens might turn to "pursuit of quality", the quality is "life quality". He suggested that pursuing an improvement in life quality was an inevitable trend in human society, and economic growth, from tangible products to intangible products, should be regarded as an important manifestation. Subsequently, the international study of life quality gradually shifted from theoretical to empirical (Boyer and Savageau, 1981; Boyer and Savageau, 2000; Massam, 2002; Myers, 1988), especially on the measurement and evaluation of "life quality". Researchers analyzing satisfaction over a whole life and 13 other specific aspects of life conducted a survey of life quality in the United States (Galbraith, 1958).

Domestic research on life quality started relatively late, and primarily from the perspective of sociology or economics, which resulted in some proposed methods and index systems to evaluate life quality (Chen, 1993; Li, 1986; Lin and Lu, 1989; Mao, 2003; SUSEST, 2002). In terms of defining life quality, Li hypothesized that it was a symbol of life and a welfare condition, including both natural and social aspects. The natural condition referred 
to beautification and purification of residential environments. In comparison, social conditions included culture, education, health, transportation, status of life services, social fashion, and social safety; Lin regarded life quality as satisfaction with a living environment and comprehensive living assessment. In contrast, Chen defined life quality based on two aspects, social supply and citizen needs, which should be comprehensive and perfect; that is, life quality was "the living adequacy and satisfaction from social provisions."

Life quality is a multidimensional concept used to measure citizen living standards and states, which incorporates the economy, society, culture, politics, and ecology, and includes both material and nonphysical components. Furthermore, life quality is both individual and social. Life quality depends on the degree of protection of objective living conditions, and on the satisfaction of subjective needs, the former being the foundation. Therefore, life quality must be evaluated based on various aspects. Learning from previous research, this study proposes an "MIOS" evaluation framework for rural life quality based on the characteristics of farmer living demand (Figure 1); income, living conditions, public service, ecological environment, culture and entertainment, neighborhood relationship, organization and management, and social security are all evaluated.

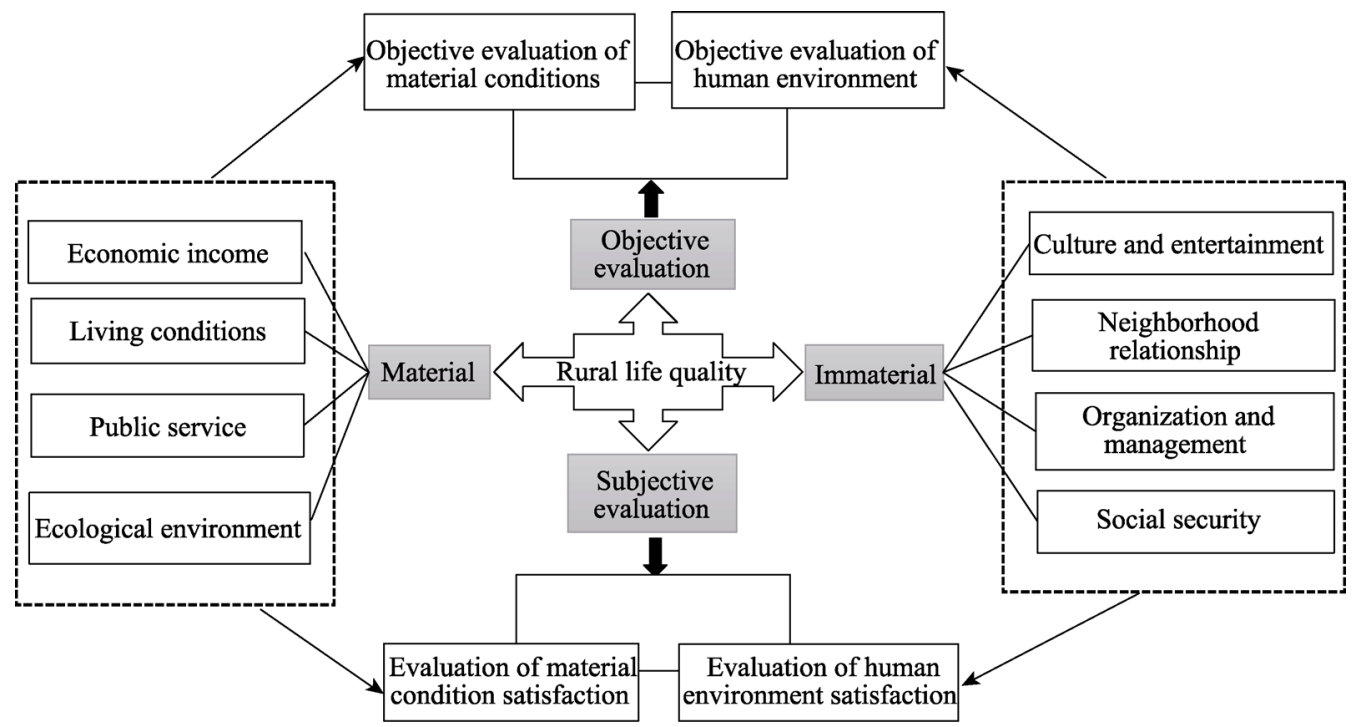

Figure 1 "MIOS" evaluation framework for rural life quality

As reflected in the objective indicators (Table 1), farmers' income and living conditions have reached a high level in China. Specifically, in 2015, rural per capita net income reached 10772 yuan, which is close to double the basic standard of a comparatively well-off life level in rural areas after deducting for the impact of price factors. Rural per capita steel or brick structures reached $33.4 \mathrm{~m}^{2}$ per person, which is more than twice the basic standard (farmer) of comparatively well-off residents in the entire country. Public service facility construction, such as transportation, water improvement, and education, has achieved significant advances, whereas indicators of social pension, environmental health, culture, and entertainment still need improvements. Most farmers are relatively satisfied with their current living conditions, according to the subjective satisfaction survey of 650 households in 50 villages in 6 provinces in the central region (He et al., 2013). 
Table 1 The objective index values of the quality of national rural life evaluation in 2015

\begin{tabular}{|c|c|c|c|}
\hline Index & $\begin{array}{l}\text { Index } \\
\text { value }\end{array}$ & Index & $\begin{array}{l}\text { Index } \\
\text { value }\end{array}$ \\
\hline Rural per capita net income (yuan/person) & 10772 & $\begin{array}{l}\text { Cumulative rate of return to water in rural } \\
\text { areas }(\%)\end{array}$ & 98.5 \\
\hline Engel's Coefficient (\%) & 37.1 & $\begin{array}{l}\text { Average number of elderly welfare agencies } \\
\text { per township }\end{array}$ & 0.81 \\
\hline $\begin{array}{l}\text { Rural per capita steel brick structure } \\
\left(\mathrm{m}^{2} / \text { person }\right)\end{array}$ & 33.4 & $\begin{array}{l}\text { Rate of rural residents participating in new } \\
\text { rural cooperative medical system }(\%)\end{array}$ & 98.8 \\
\hline Compulsory student-teacher ratio & 14.0 & Prevalence rate of sanitary toilet (\%) & 78.4 \\
\hline $\begin{array}{l}\text { Average number of technical training schools } \\
\text { for each township }\end{array}$ & 2.26 & $\begin{array}{l}\text { Expenditure on cultural and educational en- } \\
\text { tertainment }(\%)\end{array}$ & 10.5 \\
\hline $\begin{array}{l}\text { Rural access roads proportion of administra- } \\
\text { tive village }(\%)\end{array}$ & 95.5 & $\begin{array}{l}\text { Average number of comprehensive cultural } \\
\text { stations per township }\end{array}$ & 0.86 \\
\hline $\begin{array}{l}\text { Number of rural doctors and health workers } \\
\text { per thousand agricultural population }\end{array}$ & 1.47 & & \\
\hline
\end{tabular}

Sources: Rural Statistical Yearbook of China in 2016, China Statistical Yearbook in 2016, and Bulletin of Statistics on the Development of Health and Family Planning Undertakings in China in 2015. "Rural per capita steel brick structure", "average number of technical training schools for each township", "average number of elderly welfare agencies per township" are from the statistical data of 2012, "the cumulative rate of return to water in rural areas" is from 2014 , and "rural access roads proportion of administrative village" is from the second agricultural census data (2006).

Farmers' happiness scoring 90 points or more accounted for $17 \%, 80$ to 89 points accounted for $37 \%, 70$ to 79 points accounted for $31 \%, 60$ to 69 points accounted for $12 \%$, and under 60 points accounted for 3\%. With regard to public service, the satisfied and very satisfied results of farmers in terms of electricity and communications were $58 \%$ and $52 \%$, respectively, while unsatisfied and quite unsatisfied with medical, business, and cultural and leisure were $30 \%, 34 \%$, and $42 \%$, respectively. In addition, a synthesis of prior living satisfaction results in other areas (Table 2) generally indicates that current farmer life satisfaction is at the upper middle level, although there are still many regional differences. Farmers' satisfaction for living conditions, road traffic, power, and communication is relatively high. However, satisfaction is relatively low for income, culture and entertainment, health care, and

Table 2 Research and results on the satisfaction of rural life quality

\begin{tabular}{|c|c|c|c|}
\hline Research & Study area & $\begin{array}{l}\text { Research } \\
\text { time }\end{array}$ & Main findings \\
\hline $\begin{array}{l}\text { Ren et al., } \\
(2006)\end{array}$ & Chengdu & 2005 & $\begin{array}{l}\text { In the reform of household registration system, living conditions, road } \\
\text { traffic facilities, and ecological environment are rated as having high } \\
\text { public satisfaction, up to } 40 \% \text {. However, satisfaction is low in terms } \\
\text { of per capita income, industrial development, and employment and } \\
\text { social security, the proportion of general satisfaction being } 54 \%, 48 \% \text {, } \\
\text { and } 40 \% \text {, respectively. For the policy system and medical insurance, } \\
\text { dissatisfaction reached more than } 30 \% \text {. }\end{array}$ \\
\hline $\begin{array}{l}\text { Zhang and } \\
\text { Pan (2008) }\end{array}$ & Anhui & 2008 & $\begin{array}{l}\text { Farmers are not satisfied with rural production and living conditions, } \\
\text { highlighting that despite rural infrastructure construction has im- } \\
\text { proved, development has been irregular. Rural cultural infrastructure } \\
\text { has received fewer investments, and the rural financial system has lit- } \\
\text { tle effect on rural economic and social development. Furthermore, ru- } \\
\text { ral environmental pollution has become a problem, and the prospects } \\
\text { for farmland protection are poor. After } 30 \text { years of reform and open- } \\
\text { ing-up, farmers' income have been raised, but not significantly. }\end{array}$ \\
\hline
\end{tabular}


(Continued)

\begin{tabular}{|c|c|c|c|}
\hline Research & Study area & $\begin{array}{l}\text { Research } \\
\text { time }\end{array}$ & Main findings \\
\hline $\begin{array}{c}\text { Zhu } \\
\text { et al. } \\
(2009)\end{array}$ & Ningxia & 2008 & $\begin{array}{l}\text { Farmers' life satisfaction in Yanchi County; more satisfied and very } \\
\text { satisfied ratings account for } 36 \% \text {, unsatisfactory and quite unsatisfac- } \\
\text { tory ratings account for } 14 \% \text {, and generally satisfied accounts for } \\
\text { about } 50 \% \text { of the total survey. Farmer life satisfaction and income } \\
\text { have a very significant correlation. }\end{array}$ \\
\hline $\begin{array}{l}\text { Li H } \\
\text { et al. } \\
(2010)\end{array}$ & Yunnan, Henan & 2010 & $\begin{array}{l}\text { Farmer life satisfaction responses indicate general satisfaction, but } \\
\text { lower-class groups have scores that are significantly lower than those } \\
\text { of other groups in overall life satisfaction and each factor. }\end{array}$ \\
\hline $\begin{array}{l}\text { Zheng } \\
\text { (2010) }\end{array}$ & Zhejiang & 2010 & $\begin{array}{l}\text { First, under the premise of limited public financial resources, the total } \\
\text { amount of public services in rural areas is low and per capita indica- } \\
\text { tors are relatively low; therefore, the farmer satisfaction rates are not } \\
\text { high. Second, constrained by input and output factors, the comprehen- } \\
\text { sive efficiency of rural public service is low and effective supply is } \\
\text { relatively inadequate. }\end{array}$ \\
\hline $\begin{array}{l}\text { Hu and } \\
\text { Chen } \\
(2012)\end{array}$ & Jiangsu & 2011 & $\begin{array}{l}\text { The comprehensive score of rural resident satisfaction is } 3.12 \text {, indi- } \\
\text { cating general satisfaction, among which family satisfaction has the } \\
\text { highest score ( } 3.67 \text { ) and economic status has the lowest score (2.09). } \\
\text { The main factors that have a positive impact on improving the satis- } \\
\text { faction of rural residents are interpersonal relationships and govern- } \\
\text { ment public policy; however, economic status, work, and environment } \\
\text { are important factors that lower life satisfaction. }\end{array}$ \\
\hline $\begin{array}{l}\text { Li W Y } \\
(2012)\end{array}$ & Hubei & 2012 & $\begin{array}{l}\text { Farmer satisfaction with rural public infrastructure is better than in } \\
\text { other regions, but the proportion of very satisfactory responses is not } \\
\text { high; reasons for poor responses are insufficient funds for investing in } \\
\text { infrastructure, overlapping functions in agricultural institutions, low } \\
\text { investment benefits, and poor investment quality. The primary role of } \\
\text { farmers participating in construction is also unclear. }\end{array}$ \\
\hline $\begin{array}{l}\text { Li and } \\
\text { Huang } \\
(2013)\end{array}$ & Hubei & 2012 & $\begin{array}{l}\text { Farmers have a high degree of satisfaction with power supply facili- } \\
\text { ties, drinking water facilities, and transportation facilities, and are } \\
\text { generally satisfied with information and communication facilities and } \\
\text { with educational and medical facilities. The maintenance of infra- } \\
\text { structure and construction of infrastructure, irrigation and irrigation } \\
\text { facilities, waste water treatment facilities, and recreational facilities } \\
\text { are ranked as having a low degree of satisfaction. }\end{array}$ \\
\hline $\begin{array}{c}\text { Li F } \\
\text { et al. } \\
(2013)\end{array}$ & $\begin{array}{l}\text { Guangxi, He- } \\
\text { nan, Heilong- } \\
\text { jiang, Jiangxi, } \\
\text { Ningxia, Si- } \\
\text { chuan, Gansu, } \\
\text { Anhui, Yun- } \\
\text { nan, Shandong }\end{array}$ & 2013 & $\begin{array}{l}\text { The proportion of farmer life satisfaction responses that are unsatis- } \\
\text { factory and quite unsatisfactory is only } 18 \% \text {, whereas the proportion } \\
\text { of more satisfactory and very satisfactory is } 49 \% \text {, indicating a gener- } \\
\text { ally high quality of life. The life satisfaction of poor households is } \\
\text { lower than that of middle and affluent households in general. Higher } \\
\text { life satisfaction is correlated with age of householder, health, housing } \\
\text { area, types of consumer durables, road condition, village democracy, } \\
\text { and social intercourse. Finally, farmer life satisfaction first increases } \\
\text { and then decreases with increasing educational. }\end{array}$ \\
\hline $\begin{array}{l}\text { Zheng } \\
\text { et al. } \\
\text { (2017) }\end{array}$ & Jiangsu & 2014-2015 & $\begin{array}{l}\text { Farmers show a high degree of satisfaction with their rural human set- } \\
\text { tlement environment (infrastructure) and rural human settlement en- } \\
\text { vironment (natural environment), but they are less satisfied with the } \\
\text { rural ecological environment and rural eco-economy. The farmer sat- } \\
\text { isfaction scores are higher in electric power facilities, air quality, life- } \\
\text { style, water facilities, garbage collection facilities, irrigation facilities, } \\
\text { and greening status. Low satisfaction scores are in pond pollution } \\
\text { treatment, industrial pollution treatment, fertilizer and pesticide pollu- } \\
\text { tion treatment, domestic sewage treatment, eco-industrial develop- } \\
\text { ment, both human and poultry excrement treatment, eco-agriculture } \\
\text { development, and ecological services development. }\end{array}$ \\
\hline
\end{tabular}


education. Meanwhile, farmers worry about ecological environment, social security, and neighborhood relationships. Therefore, from the objective indicators and synthesis of prior living satisfaction results, subjective and objective analysis is basically consistent. However, the income is inconsistent. An important reason of this inconsistent lies in the gap between urban and rural areas and promotion of farmers' demands.

With the construction of the new socialist countryside, the life quality of farmers has been greatly improved in China. However, there are still many problems, such as the lower income of farmers compared to urban residents, unbalanced rural public service development, poor medical education, inadequate culture and entertainment, weak social security, and threatened rural ecological environment quality. Lack of industrial support and revenue sources directly affects the improvement of farmers' income level, and insufficient investment and low investment efficiency have directly influenced the improvement of public services. The degree of subject participation and the sense of belonging to a place have directly impacted the relationship between public security and neighborhood relations. Furthermore, unreasonable development and non-intensive construction directly affect the ecological environment. Rural settlements are carriers of production and living, and provide space for rural economic development, public service construction, and social interaction between farmers. Therefore, it is necessary to build a rational optimization framework of spatial organization of rural settlements to fundamentally solve the obstacles affecting the life quality of farmers.

\subsection{Rural settlement space, and the mechanisms governing its interactions with life quality}

The settlement is the spatial carrier of life quality, and life quality is an essential component of settlements; they influence and improve each other (Figure 2). The organic renewal of rural settlement space, embracing the integration of rural settlement spatial functions, optimization of spatial structure, and regulation of spatial scale, can provide farmers with better production and living places, create more opportunities for social communication, and reduce facilities use cost. Concurrently, these changes can beautify the eco-landscape environment, to improve the life quality of farmers, and lead to an accumulation of more construction capital, create higher space requirements, and cultivate stronger creative abilities for the organic renewal of rural settlement space. The goal is to achieve a benign cycle between spatial optimization of rural settlements and sustainable enhancement of life quality.

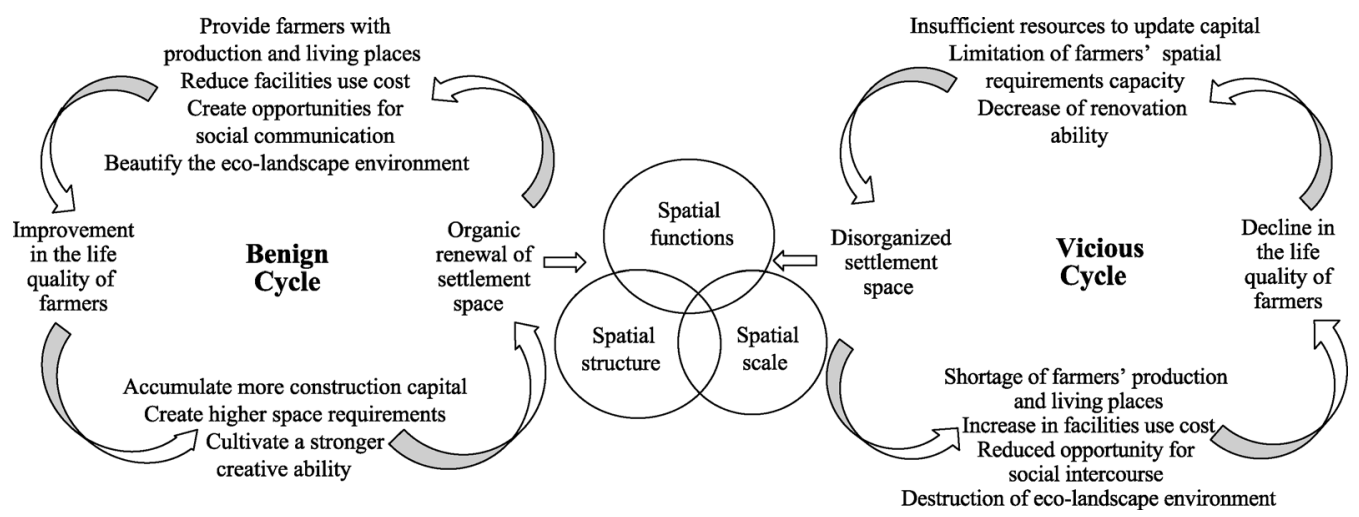

Figure 2 Two-way interactive mechanisms between rural settlement space and life quality 
In contrast, disorganized rural settlement space and lack of space function will lead to shortages in farmer production and living places, a reduction in opportunities for social intercourse, decreases in facility construction, and use cost increases due to irrational scaling and clustering. Poor planning can destroy the eco-landscape environment, so as to cause a decline in the life quality of farmers, which will lead directly to insufficient resources to update capital, limitation of farmer spatial requirements capacity, and decrease in ability to renovate. This chaotic settlement space results in a vicious cycle of disordered rural settlement spaces and declining life quality for farmers. The two-way interactive mechanism between rural settlement space and life quality reveals the significance of spatial optimization of rural settlements based on farmers' life quality.

\section{The optimization framework for the spatial organization of rural settle- ments based on life quality}

Meeting the requirements for farmer production and living, and improving their life quality is a basic starting point for optimizing the spatial organization of rural settlements. To achieve this goal, we must first ensure the optimization and improvement of functional services of settlements. Optimizing the spatial organization of rural settlements is actually an adjustment process that proportions the relationships and spatial combination of spaces that carry different functions. In comparison, optimizing the spatial organization of the rural settlement system means arranging the spatial relationships of different settlements with different leading functions. The scale of the settlement space should be conducive to the function of the settlement, and conform to their spatial organization; therefore, the following sections are primarily based on integrating the spatial function while optimizing spatial structure and regulating the spatial scale to create an optimization mode and framework for the spatial organization of rural settlements based on life quality.

\subsection{Integration of spatial function based on life quality}

Function integration has been found in rural settlements (Zhu X H et al., 2010). The most basic simple and busy rural life mode of beginning well before sunrise and ending at sunset, is just for survival, promoting the integration of traditional production and residential functions. As the rural economy has transformed and living standards have improved, diverse lifestyles that include work, business, communication, recreation, and entertainment have gradually emerged; the rural settlement function has inevitably changed from homogeneous isomorphism to heterogeneous variety (Luo and Li, 2011), shifting from integration of traditional production and residential functions into a new multi-functional integration.

Organic multi-functional integration is beneficial for improving the convenience of production and life of farmers, enriching public life, increasing spatial vitality, cultivating good neighborhood relationships, and making intensive use of space. In contrast, disorganized multi-functional integration may lead to ecological damage, rural loss, spatial inefficiency, and other issues, which decreases the quality of life. Therefore, we can reasonably optimize the function of the settlement space according to the needs of different stages of development, including functional adjustment, implantation, and upgrading (Chen and Lu., 2010). Based on the transition locus of rural territorial function (Liu et al., 2012), 
the types of rural settlement spatial functions can be divided into maintaining livelihoods, developing industry, and optimizing quality, in which agricultural production and living are categorized as maintaining livelihood; industrial production, tourism, trade, and service are categorized as developing industry; and public service, culture, and leisure are categorized as optimizing quality. Optimizing the spatial function of rural settlements based on life quality requires us to promote maintaining livelihood, integrate developing industry, and implant optimizing quality (Figure 3). For livelihood maintenance, it is better to enhance the function and improve the efficiency of agricultural production and quality of agricultural products to ensure food safety, while also improving the living conditions of residents to realize farmer innovations in household function. To develop industry, it is best to retain and promote functions in tourism and processing of agricultural products that are adapted to rural development, remove industrial production functions that are in conflict with rural development or cause pollution, and adjust business services based on economic logic. Methods for optimizing quality include foster cultural and leisure functions, organizing public activities, creating neighborhood communication opportunities, improving public service function, and protecting education, medical care, health, social security, and infrastructure services according to the requirements of rural modernization, and equalizing urban and rural residential life to improve resident culture, facilities and neighborhood satisfaction.

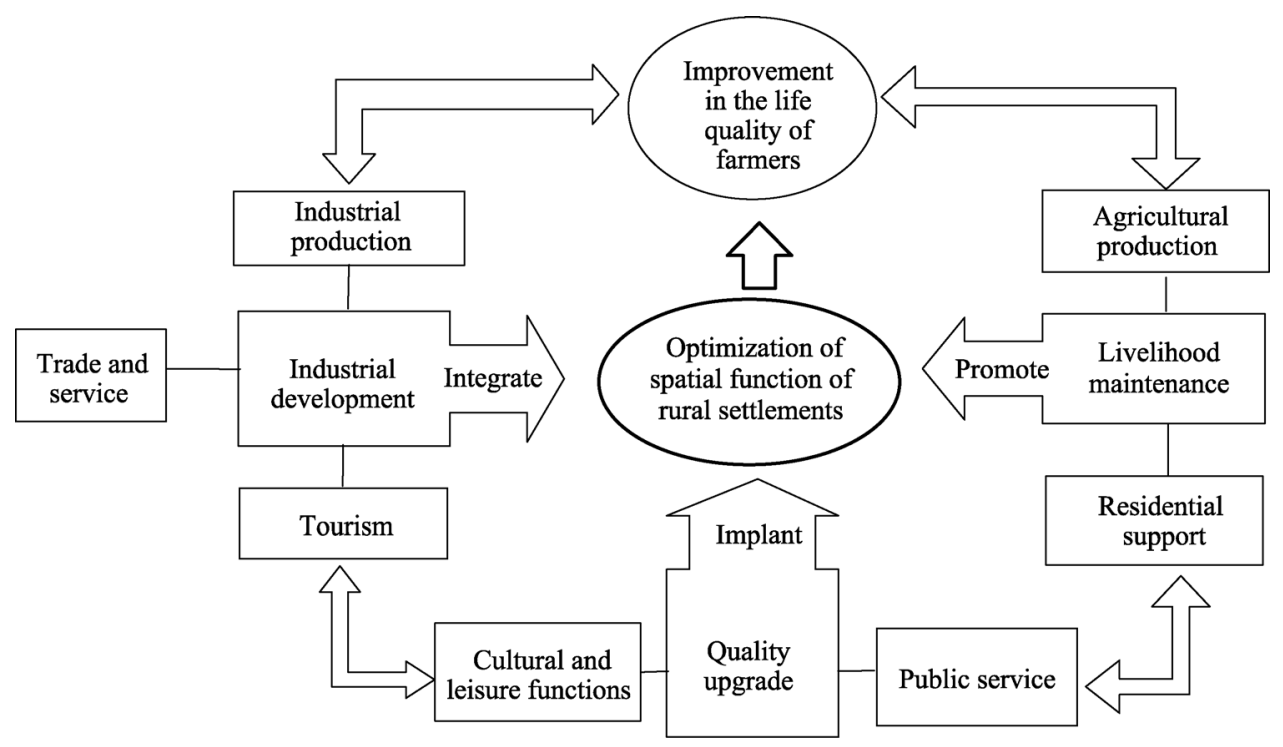

Figure 3 Integrated spatial function of rural settlements based on life quality

\subsection{Optimizing spatial organization based on life quality}

Decentralization, depopulation, hollowing, intermixing, and the simple mechanical concentration of town apartments separated from actual rural areas are outstanding problems in the rural settlement space of China. These problems are clearly related, so optimizing the spatial organization of rural settlements is a fundamental factor. The spatial organization of rural settlement involves internal settlement and settlement system structure; notably, the former is a problem of proportion relationships and spatial combinations of spaces with differing functions, while the key aspect of the latter is in the spatial location and correlation 
of each settlement in the system.

Optimizing the internal spatial structure of rural settlements based on life quality (Figure 4), can be based on the integration of spatial function of rural settlements, and realizes an organic combination of spatial types in functional integration. Rural settlement space can be divided into living, production, ecological, service, social intercourse, and recreational spaces. Judging from the current situation, the continuous improvement of rural life quality in China has increased the sense of belonging, neighborhood harmony, and cultural identity for farmers in rural settlements. However, agricultural and ecological spaces are being occupied or destroyed due to urbanization and non-agricultural rural activities.

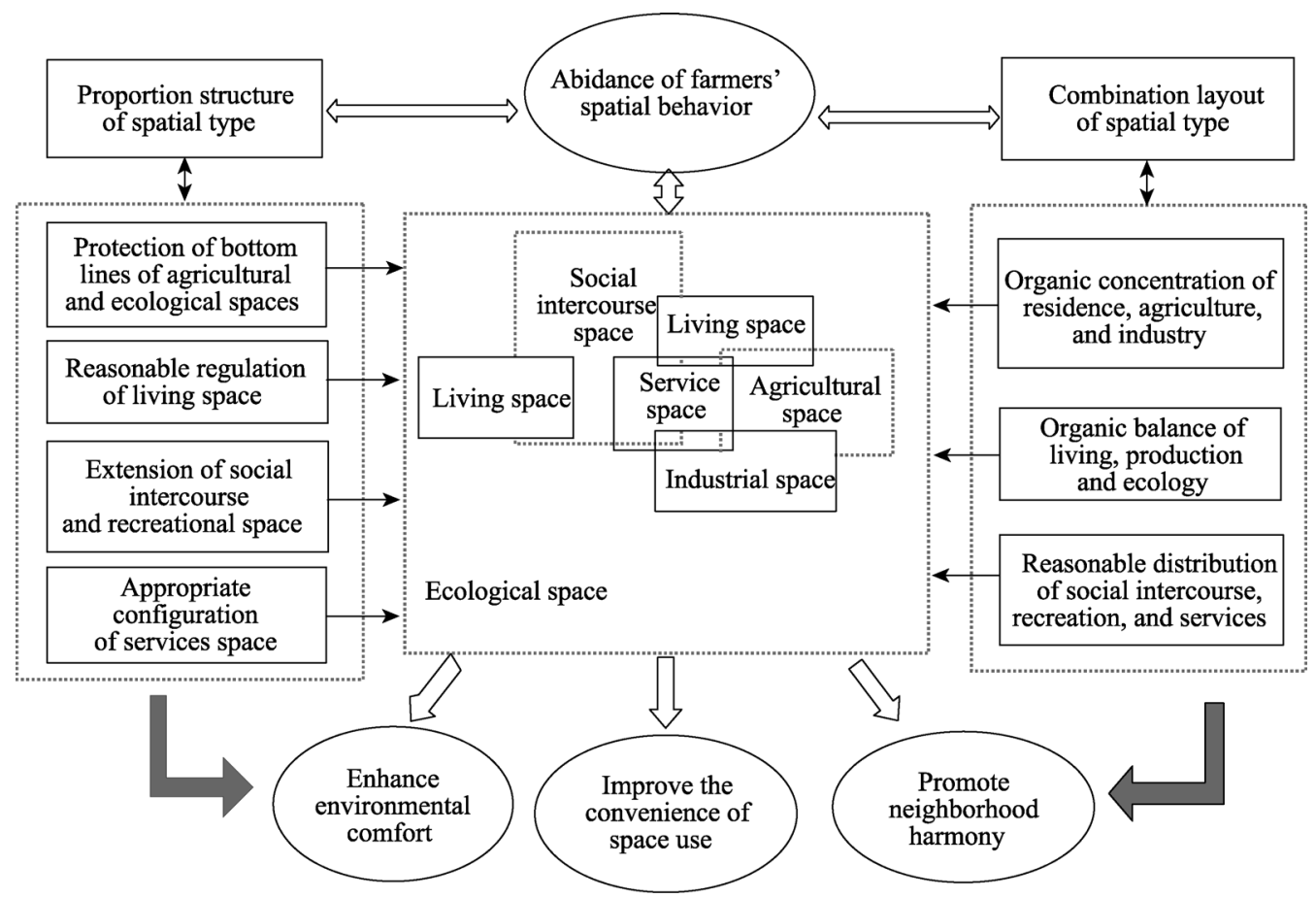

Figure 4 Optimizing the internal spatial organization of rural settlements based on life quality

Therefore, the focus of optimizing internal spatial structure of settlements in terms of proportion is protecting agricultural and ecological spaces, expanding social intercourse and recreational spaces, and moderately allocating services space to control the size of each space type according to the regional situation. The goal is to ensure spatial function diversity and enhance the comfort of the spatial environment. The optimal combination of internal spatial type in settlements should abide by the spatial behavior habits of farmers for living, consumption, employment, and social interaction (Massam, 2002). This optimal combination should gradually achieve a communalization of living, large-scale agriculture and grouped industrial spaces, and the reasonable distribution of social intercourse, recreational, and services spaces, to achieve an organic balance of living, production, and ecological spaces. In summary, optimization should improve the efficiency and convenience of space use.

Optimizing the spatial structure of rural settlement systems based on life quality, aimed at improving the coordination of the settlement system, needs to effectively integrate the functional hierarchical structure of the rural settlement system and promote the interaction 
between rural settlements. The objective is to build a stable, coordinated, and sustainable rural settlement system. Optimizing the spatial organization of rural settlements is essentially a process of relocation and function adjustment, where transforming settlements includes individual and group relocation and functional changes. During the process, we should gradually relocate underdeveloped villages that are scattered and unsuitable for living, retain some normal moderate-scale villages suitable for living, enlarge important villages, expand parts of key villages that have the appropriate housing and gathering potential, and build some new villages that have superior and well-equipped locations (Figure 5). The resettlement function should be modified based on the advantages and disadvantages of the location and development foundation, and form a functional level of structure characterized as "comprehensive village - featured village." This concept highlights the integrity of functional structure and external radiation of the comprehensive village, while emphasizing the unique aspects of the featured village. To better promote the interactions of rural settlement, relocation should consider farmer communication habits and behavior, the impact of traffic conditions on farmer production and life, and the influence of geographical factors. In summary, the spatial organization of rural settlements connected by rural roads should employ a spatial organization optimization mode based on life quality.

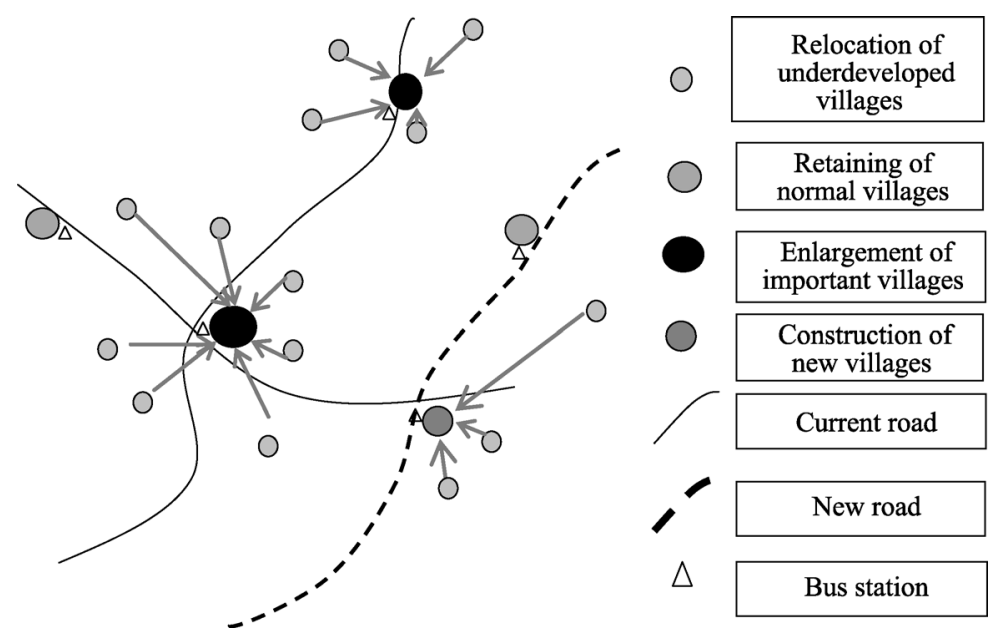

Figure 5 Optimizing the spatial organization of settlement system connected by rural roads

\subsection{Regulating the spatial scale of rural settlements based on life quality}

The settlement single-scale and distance between settlements are two key indices for describing the spatial scale of rural settlements. The settlement single-scale is the settlement self size, while the distance between settlements reflects the spatial morphology of the settlement system. The appropriate settlement scale can greatly improve rural resident daily travel and facilities utilization convenience, increase the efficiency of construction, and decrease use costs of public service facilities for education and medical care. A reasonable distance between settlements can effectively facilitate rural public transport, improve the overall operation efficiency of the settlement system, and promote interactions between settlements. To improve the life quality of farmers, the requirements for farmers' production and living, and the ability to control the environment are both important for regulating the spatial scale of rural settlements. Factors that are incorporated in those requirements include 
the environment and location conditions, travel mode and distance perception, productivity level and mode of production, neighborhood relationship and psychological identity, facilities distribution threshold, and organizational management benefits (Figure 6). In practice, determining the spatial scale of a settlement is closely related to regional natural conditions, the level of development and functional orientation, and geographical differences.

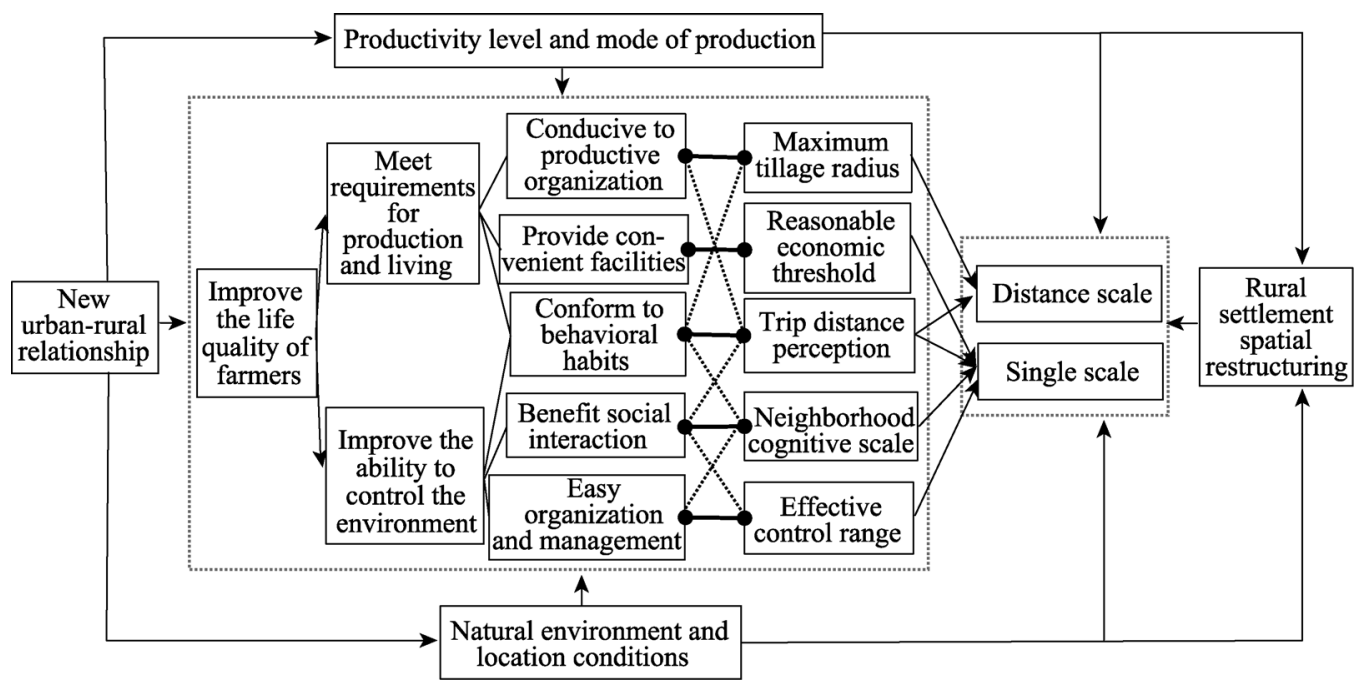

Figure 6 Diagram outlining the mechanisms influencing the spatial organization of rural settlements based on life quality

\section{Optimization mode for the spatial organization of rural settlements based on life quality}

\subsection{Basic RROD concepts and spatial structures}

Guided by the basic optimization mode for the spatial organization of rural settlements based on life quality, a new optimization model is established, termed the Rural Road-Oriented Development Model (RROD model) (He et al., 2014). In the RROD model, rural settlements rely on the layout of rural roads, and form a new type of rural community that is perfect in function and moderate in scale. Within a certain area, there are many RRODs that employ a dominance hierarchy and reasonable layout, and may be associated with each other. A RROD system is based on the regional geographical environment conditions and relies on the rural road system,.

An RROD generally consists of three to six functional groups, while the functional group type can be divided into residential, integrated, and special functions (Figure 7). The main residential function is living. The integrated function group can be a collection of residential, tourism, and public services and other functions. The special function group is dedicated to the optional space unit comprised of industrial production, tourism, and other special features. The logical arrangement of functional groups in space can achieve the organic coordination of living, production, and ecological spaces. The RROD has the advantages of convenient transportation, drainage, power supply, sanitation facilities, convenient production and living of farmers, harmonious neighborhoods, and comfortable living environments. 
Public service centers are located in the integrated function group, arranged with kindergarten, primary school, medical center, integrated store, cultural station, elderly activity center, and other facilities. According to the degree of facility improvement and status difference in the RROD system, the overall RROD can be divided into the central RROD, general RROD, and base RROD. Based on the industrial structure and functional differences, the RROD can be divided into traditional agriculture, modern agriculture, mixed workers and farmers, integrated service, and tourism-oriented. Different levels and types of RROD are coordinated to form the RROD system.
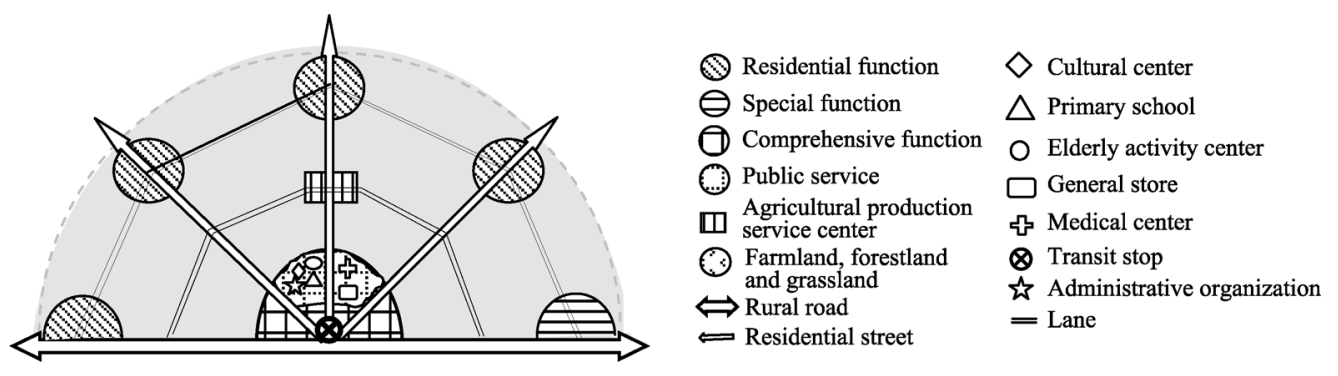

Figure 7 Diagram outlining the basic structure of a complete RROD unit

\subsection{RROD parameter values}

The spatial scales of rural settlements are regulated based on life quality, unit radius, population size, and distance between RRODs, and should be considered during RROD mode regulation. The maximum social circle of farmer neighborhood interactions and maximum power radiation range of organization and management should determine the RROD scale, which can be controlled within a certain range to form a sense of identity and belonging. Furthermore, the RROD scale can play an important role as public institutions organize personnel, govern villages, and set policies. According to existing research (Guo and Chen, 2017; Li, 2007; Wang, 2010; Zhang and Xiao, 2009), the internal population size of an RROD should be in the range of 300 to 900 households. Conversely, based on the minimum threshold requirements for rural public service facilities, the settlement population should reach a certain size to achieve economies of scale, improve facility utilization, and reduce waste. In general, the minimum service population threshold size for public service facilities, such as primary schools, clinics, and integrated stores, is around 1500 people (Hui et al., 2010), and the service radius of these public service facilities is also directly related to the RROD unit radius. Generally, 5-10 min and 400-800 m, at a walking speed of $5 \mathrm{~km} / \mathrm{h}$, is an appropriate walking scale; beyond this scale, even if there is a good walking environment, it is difficult to stimulate the residents' willingness to walk. Therefore, the service radius of the public service facility is basically within this range, and the unit radius of a RROD should also be controlled within $800 \mathrm{~m}$. Travel within a settlement is mainly on foot, but travel between settlements is usually by bus or bicycle. Setting a suitable travel speed of $10-20 \mathrm{~km} / \mathrm{h}$, the travel time distance is $10-15 \mathrm{~min}$; then, the maximum travel distance is 5 $\mathrm{km}$, and the distance between adjacent RRODs should be controlled to within $5 \mathrm{~km}$. More importantly, travel mode and distance perception will also affect the tillage radius. The agricultural production function is the most basic function in the countryside, for both traditional agricultural time and modern rural economic transformations, and a reasonable 
tillage radius must be considered in determining the RROD spatial scale. In general, farmers cultivate at a time distance of about $15 \mathrm{~min}$; therefore, with agricultural transport support, the maximum tillage radius can reach $6.25 \mathrm{~km}$, calculated at $25 \mathrm{~km} / \mathrm{h}$; under walking conditions, the maximum tillage radius is about $1.25 \mathrm{~km}$, calculated at $5 \mathrm{~km} / \mathrm{h}$ (Jiao et al., 2006; Tang et al., 2014; Zhao and Hui, 2008). These values directly affect the distance scales between RROD units. Initial calculations indicated an RROD unit radius of 400-800 m, RROD population size as 1500-3000 people, and distance between RRODs as 3.5-5.0 km (Table 3). However, this initial calculation is based on a general assumption of homogeneity, and does not fully take into account the differences in topography and economic development level, and their influence on RROD mode. Therefore, particularly in mountainous and hilly areas, we should adjust the spatial scale according to rural road facilities network construction.

Table 3 Parameter values for the RROD spatial scale in different landform areas

\begin{tabular}{cccc}
\hline & \multicolumn{2}{c}{ RROD scale } & RROD distance (km) \\
\cline { 2 - 3 } & Unite radius $(\mathrm{m})$ & Population size (person) & $4.0-5.0$ \\
Plain & $650-800$ & $2000-3500$ & $3.5-4.5$ \\
Hilly & $450-700$ & $2000-3000$ & $4.5-5.5$ \\
Mountain & $400-600$ & $1500-2500$ & \\
\hline
\end{tabular}

\subsection{The important role of the RROD model in improving the life quality of rural set- tlements}

In accordance with the theory of science of human settlements proposed by Academician $\mathrm{Wu}$ Liangyong (2001), the human settlement environment consists of five major elements: natural, human, social, living, and supporting network. Decentralization, depopulation, hollowing, intermixing, and the simple mechanical concentration of the town apartments separated from true rural areas have largely destroyed the organic combination of the five major elements, which is an important challenge in improving the quality of rural life. The RROD model focuses on the organic synergy of these five factors and forms the "Five Collaborative Effect":

(1) Protect the natural ecological foundation of settlement development through the protection and promotion of natural landscape patterns.

(2) Promote the rational distribution of population in urban and rural areas by guiding the rural population to gather logically in rural areas, and gradually developing into a service center and growth center of the village, and then controlling the rural population (especially young people) pouring into cities, restraining rural decline.

(3) Reconstruct the social relationships within the settlement, constructing a harmonious neighborhood environment, and improving the sense of living belonging through proportion and layout optimization of living, service, social intercourse, and leisure spaces.

(4) Effectively organize the spatial connections in the rural settlement system and promote the interaction among rural settlement units by reasonably planning the scale of rural settlement units and the distance among them.

(5) Improve the service capability of the settlement support network, reduce the use cost for facilities, and enhance the convenience of the rural residents' production and living using road locations, a reasonable radius for services, and an economic threshold to guide the scale 
of settlement units and configuration of various facilities.

In summary, the RROD model can guide rural settlement to realize multiple targets, which strengthens natural ecosystem service functions, enhances the livelihood maintenance function, optimizes the industrial development function, and implants the quality optimizing function, to improve the life quality of rural residents. Implementing the RROD model can result in the ideal goal of gradually equalizing the residential lives of urban and rural citizens in the coordinated development of urban and rural areas (Figure 8).

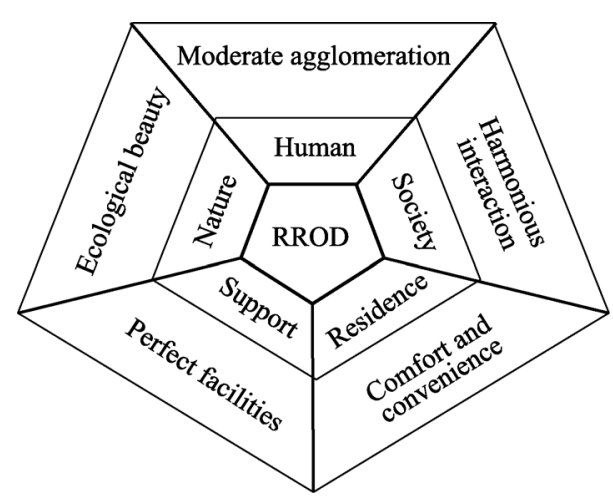

Figure 8 Diamond diagram of the "Five Collaborative Effect" around the RROD model to improve the quality of rural life

\section{Conclusions and discussion}

(1) With the promotion of new national urbanization and country construction strategies, the rural economy and society are facing a drastic transformation. Key problems in this transformation are i) understanding the optimal scale problem and spatial structure of rural settlements, and ii) identifying the spatial organization of rural settlements that can provide better settlement functions. Addressing these problems is urgently required. Rural development has been gradually transformed from basic survival to the pursuit of life quality in China; therefore, studying the spatial organization of rural settlements based on life quality is particularly prescient as we explore human development.

(2) Optimizing rural settlements is an important measure for coping with rural decline and improving the quality of rural life and attractions. With the construction of a new socialist countryside, the life quality of farmers has been greatly improved in China. However, many problems remain, such as the lower incomes of farmers compared to urban residents, imbalanced rural public service development, poor medical education, limited culture and entertainment, weak social security, and threats to rural eco-environmental quality. Settlements are the spatial carriers of life quality, and life quality is an essential component of settlements; they influence and improve each other, following a two-way interactive mechanism. Building a rational optimization framework for the spatial organization of rural settlements is required to fundamentally solve the obstacles affecting the life quality of farmers.

(3) The optimization mode for the spatial organization of rural settlements based on life quality embraces the integration of rural settlement spatial functions, optimization of spatial structure, and regulation of spatial scale. The integration of rural settlement spatial functions promotes livelihood maintenance, integrates industrial development, and engages quality optimization based on the transition locus of the rural territorial function. The optimization of spatial structure for rural settlements optimizes agricultural and ecological spaces, expands social intercourse and recreational spaces, and moderately allocates services space, which reasonably proportions the internal spatial organization of a settlement. The organic concentration of living, agricultural, and industrial spaces, the organic growth of social intercourse, recreational, and services spaces, and the organic balance of living, production, 
and ecological spaces can achieve an optimal combination of internal spatial types in settlements. This forms a functional structure, the "comprehensive village - featured village," and creates a spatial organization mode for settlements connected by rural roads using relocation and function modification. These changes are implemented through the destruction of underdeveloped villages, retention of normal villages, expansion of important villages, and construction of new villages. To regulate the spatial scale, it is necessary to guide both the settlement size and the distance between settlements.

(4) As an optimization mode for the spatial organization of rural settlements based on life quality, the RROD model incorporates the RROD and RROD system as the basic framework, supporting the organic integration of the spatial function, organic balance of spatial structures, and organic constraints from the spatial scale. It can provide theoretical guidance for the construction of rural complexes. In addition to guiding the optimization mode for the spatial organization of rural settlements based on life quality, the model has also inspired some of new types of rural agglomeration. However, it still faces the challenge of planning and design, economic cost, policy system, and regional environment differences, which need more specific design criteria, comprehensive investment plans, detailed action guidance, and a better policy framework. Here, the RROD is proposed only as a preliminary theoretical framework based on homogeneous assumptions, to guide more detailed and thorough arguments and research. Applying a typical sample area to this model is the subject of future work, where it can be further developed to better test and improve the practice mode.

(5) The internet and rapidly developing information technology are becoming important aspects of the productive lifestyles of rural residents in the new era, and important driving factors of the spatial change of rural settlements. Large geographical spatio-temporal datasets are becoming new data sources to study the production and life behavior of urban and rural residents and spatial changes in urban and rural areas. Making full use of large data to comprehensively understand the behavioral characteristics of urban and rural residents, discuss the changing spatial orientations of rural settlement under the influence of the internet and information technology, and construct more livable and attractive rural settlements in the information age are topics that should be addressed in future research.

\section{References}

Amarasinghe U, Samad M, Anputhas M, 2005. Spatial clustering of rural poverty and food insecurity in Sri Lanka. Food Policy, 30(5/6): 493-509.

Anthopoulou T, Kaberis, Petrou M, 2017. Aspects and experiences of crisis in rural Greece. Narratives of rural resilience. Journal of Rural Studies, 52: 1-11.

Antrop M, 2004. Landscape change and the urbanization process in Europe. Landscape and Urban Planning, 67(3): 9-29.

Bański J, Wesołowska M, 2010. Transformations in housing construction in rural areas of Poland's Lublin region: Influence on the spatial settlement structure and landscape aesthetics. Landscape and Urban Planning, 94(2): $116-126$.

Boyer R, Savageau D, 1981. Places Rated Almanac. Chicago: Rand McNally.

Boyer R, Savageau D, 2000. Places Rated Almanac. Chicago: Rand McNally.

Chen M, Lu J C, 2010. Compound characters and adaptive restructuring of village space. Planners, 26(11): 44-48. (in Chinese) 
Chen Y F, Sun H, Liu Y S, 2010. Reconstruction models of hollowed villages in key agricultural regions of China. Acta Geographica Sinica, 65(6): 727-735. (in Chinese)

Chen Y P, 1993. Comparative analysis of two evaluation methods of life quality. Social Sciences in Guangdong, (3): 38-45. (in Chinese)

Fang Y G, Liu J S, 2009. Cultural landscape evolution of cluster agricultural village: The case of Yukou village in Shandong province. Geographical Research, 28(4): 968-977. (in Chinese)

Feng W Y, Chen X M, 2003. Analysis on the rural settlement expansion of the Jinzhong plain. Human Geography, 18(6): 93-96. (in Chinese)

Flynn M, Kay R, 2017. Migrants' experiences of material and emotional security in rural Scotland: Implications for longer-term settlement. Journal of Rural Studies, 52: 56-65.

Galbraith J K, 1958. The Affluent Society. Boston: Houghton Mifflin.

Gilman R, 1991. The eco-village challenge. Living Together, 29(2): 10-11.

Górka A, 2016. Landscape rurality: New challenge for the sustainable development of rural areas in Poland. Procedia Engineering, 161: 1373-1378.

Guo H C, Wang Y C, 1999. Retrospect and developing trend of agriculture geography in China. Economic Geography, 19(6): 1-6. (in Chinese)

Guo L K, Chen Y F, 2017. Estimation of reasonable scale of rural settlements in plain agricultural areas: A case study of Yucheng, Shandong Province. Journal of Ecology and Rural Environment, 33(1): 47-54. (in Chinese)

Hai B B, Li X J, 2013. Review on researches of rural settlement space in China since 1900. Journal of Henan University (Natural Science), (6): 635-642. (in Chinese)

He Y H, Tang C L, Zhou G H, 2014. The new model of the spatial structure of rural settlements: RROD. Geographical Research, 33(9): 1716-1727. (in Chinese)

He Y H, Zeng S S, Tang C L et al., 2013. Differentiation characteristics and forming mechanism of rural settlements in Central China. Acta Geographica Sinica, 68(12): 1643-1656. (in Chinese)

Hidding M C, Teunissen A T J, 2002. Beyond fragmentation: new concepts for urban-rural development. Landscape and Urban Planning, 58: 297-308.

Hoggart K, Paniagua A, 2001a. What rural restructuring? Journal of Rural Studies, 17(1): 41-62.

Hoggart K, Paniagua A, 2001b. The restructuring of rural Spain? Journal of Rural Studies, 17(1): 63-80.

Hu R H, Chen Y, 2012. Statistical analysis of rural life satisfaction in Jiangsu Province. Chinese Rural Economy, 28(1): 80-91. (in Chinese)

$\mathrm{Hu}$ Z, Liu P L, Cao S Q, 2013. Spatial pattern of landscape genes in traditional settlements of Hunan Province. Acta Geographica Sinica, 68(2): 219-231. (in Chinese)

Hu Z C, Peng J, Du Y Y et al., 2016. Reconstructing hollow villages in the view of structural reform of the supply side. Acta Geographica Sinica, 71(12): 2119-2128. (in Chinese)

Hui Y A, Zhang Y S, Xu M, 2010. Study on functions and appropriate scale of rural settlement: A case study of South Ditch Valley of Ansai County in Yan'an. The Journal of Humanities, (3): 183-187. (in Chinese)

Huo R L, Yang Y D, Man Z M, 2016. Pattern evolution of settlement space in the Zhangjiuhe Basin, Yunnan province, during the past 300 years. Geographic Research, 35(9): 1647-1658. (in Chinese)

Jiao Y M, Hu W Y, Su S H, 2006. Spatial pattern and farming radius of Hani settlements in Ailao Mountain using GIS. Resources Science, 5(3): 66-72. (in Chinese)

Li B, 2007. Scale governance-Structure and function of large-scale village's organizations: An investigation of Caocun in Zhejiang Province abstract [D]. Hangzhou: Zhejiang Normal University. (in Chinese)

Li B H, Liu C M, Zeng J X, 2009. An evaluation on the satisfaction degree and optimization strategy of rural human settlements: A case study of Jiuheyuan Town in Shishou City. Human Geography, 24(1): 28-32. (in Chinese)

Li B H, Liu P L, Dou Y D, 2014. Analysis of self-organizing evolution mechanism of rural human settlement system. Economic Geography, 34(9): 130-136. (in Chinese)

Li B H, Zeng J X, 2009. Research on rural human settlement environment based on the changes of the house- 
holders' spatial behaviors. Geography and Geo-Information Science, 25(5): 84-88. (in Chinese)

Li F, Tang L X, Yu L R et al., 2013. The analysis of farmers' life satisfaction and its influencing factors: Based on 10 villages cross-sectional data. Northwest Population Journal, (1): 41-46. (in Chinese)

Li H, Bai X J, 2010. The study on the present situation and influencing factors of life satisfactory of China farmers in the angle of social recognize. Research World, 23(7): 27-30. (in Chinese)

Li H B, Zhang X L, 2012a. A review and trend on rural settlement geography abroad. Human Geography, 27(4): 103-108. (in Chinese)

Li H B, Zhang X L, 2012b. Spatial extension in the context of urban and rural development: Village recession and reconstruction. Reform, (1): 148-153. (in Chinese)

Li Q L, Ma X D, Shen Y, 2012. Analysis of spatial pattern of rural settlement in northern Jiangsu. Geographical Research, 31(1): 144-154. (in Chinese)

Li W Y, 2012. Study on evaluation of farmers satisfaction of the rural public infrastructure. Journal of Chongqing University (Social Science Edition), (4): 9-15. (in Chinese)

Li X J, 2013. Development evaluation and new framework proposal of economic geography. Geographical Research, 32(10): 1865-1877. (in Chinese)

Li X J, Luo Q, Fan X S, 2009. A study on the formation and evolution of specialized rural villages. China Soft Science, 24(2): 71-80. (in Chinese)

Li X J, Shi H N, 2008. Rural development in the less developed region of China: A household perspective. Human Geography, 22(1): 1-6. (in Chinese)

Li X T, Huang H Y, 2013. Analysis of farmers' satisfaction about current rural infrastructure in the region of central China. Journal of China Agricultural University, (5): 205-212. (in Chinese)

Li Y, Chen Z X, 1994. A spatial analysis of the system of rural communities in southern Shaanxi. Human Geography, 9(3): 13-21. (in Chinese)

Li Y N, 1986. The Socialist Political Economics. Beijing: The Commercial Press. (in Chinese)

Lin N, Lu H L, 1989. Investigation of model of structure model about index of society and life quality: A research about the life of Shanghai city residents. Social Sciences in China, 10(4): 75-97. (in Chinese)

Liu S Q, 2006. Ecological Study of Rural Settlements: Theory and Practice. Beijing: China Environmental Science Press. (in Chinese)

Liu Y S, 2007. Rural transformation development and new countryside construction in eastern coastal area of China. Acta Geographica Sinica, 62(6): 563-570. (in Chinese)

Liu Y S, 2013. Overcome the "rural disease" in the process of new urbanization. Weishi (Modern Management), (11): 21. (in Chinese)

Liu Y S, Li Y H, 2017. Revitalize the world's countryside. Nature, 548: 275-277.

Liu Y S, Liu Y, Zhai R X, 2009. Geographical research and optimizing practice of rural hollowing in China. Acta Geographica Sinica, 64(10): 1193-1202. (in Chinese)

Liu Y S, Long H L, Zhang X L et al., 2011. Research progress and prospect in the disciplines of agricultural geography and rural development in China. Progress in Geography, 30(12): 1498-1505. (in Chinese)

Liu Y S, Yang R, Li Y H, 2013. Potential of land consolidation of hollowed villages under different urbanization scenarios in China. Journal of Geographical Sciences, 23(3): 503-512.

Liu Z Q, Zhou A L, Lu Q, 2012. The transition of rural territorial leading function and the classification of rural development stages. Journal of Arid Land Resources and Environment, 26(4): 49-54. (in Chinese)

Long H L, 2013. Land consolidation and rural spatial restructuring. Acta Geographica Sinica, 68(8): 1019-1028. (in Chinese)

Long H L, 2014. Land consolidation: An indispensable way of spatial restructuring in rural China. Journal of Geographical Sciences, 24(2): 211-225.

Long H L, Li Y R, Liu Y S, 2009. Analysis of evaluative characteristics and their driving mechanism of hollowing villages in China. Acta Geographica Sinica, 64(10): 1203-1213. (in Chinese)

Long H L, Liu Y S, Zhang X L et al., 2016. Recent progress in agricultural geography and rural development 
research. Progress in Geography, 69(8): 1145-1158. (in Chinese)

Long H L, Zou J, Pykett J et al., 2011. Analysis of rural transformation development in China since the turn of the new millennium. Applied Geography, 31: 1094-1105.

Luo Q, Li X J, 2011. Study on the evolution of farmer interaction network: In the case of Mengzhai village, Henan Province. Reformation \& Strategy, 27(4): 93-96. (in Chinese)

Ma E P, Li T S, Wei Q R, 2016. Mechanism of change in spatial pattern of rural settlements in peri-urban areas of China: A case study of Kangdu Village in the college town of south Xi'an. Progress in Geography, 35(7): 816-828. (in Chinese)

Mao D Q, 2003. The Study on the Theory and Method of Quality Assessment of Urban Life. Beijing: Atomic Energy Press. (in Chinese)

Massam B H, 2002. Quality of life: Public planning and private living. Progress in Planning, 58(3): 141-227.

McKenzie P, Cooper A, McCann T et al., 2011. The ecological impact of rural building on habitats in an agricultural landscape. Landscape and Urban Planning, 101(3): 262-268.

Montis A D, Ledda A, Serra V et al., 2017. A method for analysing and planning rural built-up landscapes: The case of Sardinia, Italy. Land Use Policy, 62: 113-131.

Myers D, 1988. Building knowledge about quality of life for urban planning. Journal of the American Planning Association, 54(Summer): 347-358.

Nelson P B, 2001. Rural restructuring in the American West: Land use, family and class discourses. Journal of Rural Studies, 17(4): 395-407.

Qiao J J, Li X J, Ge Z, 2009. Village-level commercial economic activity space based on 580 rural households surveyed. Economic Geography, 29(5): 817-922. (in Chinese)

Ren P, Zhou J M, He W et al., 2006. Marking investigations in peasants' satisfaction in the course of integration of urban and rural. Yunnan Geographic Environment Research, (1): 75-78. (in Chinese)

Rostow W W, 1971. Politics and the Stages of Growth. Cambridge: Cambridge University Press, 17.

Shanghai Urban Social and Economic Survey Team (SUSEST), 2002. Building evaluation index system of quality of life for urban residents. Shanghai Statistics, (12): 16-19. (in Chinese)

Tan X L, Yu S Y, Ouyang Q L et al., 2017. Assessment and influencing factors of rural hollowing in the rapid urbanization region: A case study of Changsha-Zhuzhou-Xiangtan urban agglomeration. Geographical Research, 36(4): 684-694. (in Chinese)

Tang L J, Wang D Y, Wang L L, 2014. Rational distribution of rural settlements based on farming radius: A case study in rural-urban construction land in Yiyuan County, Shandong Province. China Population, Resources and Environment, 24(6): 59-64. (in Chinese)

Tian Y P, 2011. The dilemma of urban-rural integration under the village of “depopulation”. Zhejiang Academic Journal, 49(5): 31-35. (in Chinese)

Wang Y, Li G B, 2011. Functional transformation and spatial restructuring of rural settlements in southern Jiangsu: A case study of Suzhou. City Planning Review, 35(7): 54-60. (in Chinese)

Wang Y F, 2010. Clan, size and average income in villages: Evidence from China. Nankai Economic Studies, (3): 64-72. (in Chinese)

Woods M, 1997. Discourses of power and rurality: Local politics in Somerset in the 20th century. Political Geography, 16(6): 453-478.

Wu L Y, 2001. Introduction to Sciences of Human Settlements. Beijing: China Architecture \& Building Press. (in Chinese)

Yang R, Liu Y S, Long H L et al., 2015. Research progress and prospect of rural transformation and reconstruction in China: Paradigms and main content. Progress in Geography, 34(8): 1019-1030. (in Chinese)

Zeng J X, Yang Q Q, Liu Y J et al., 2016. Research on evolution and influential mechanism for rural human settlement in national key ecological function areas: A case of Lichuan. Human Geography, 31(1): 81-88. (in Chinese)

Zhang D Y, Pan L, 2008. Thirty years' reform in rural area: A survey in Anhui Province. Chongqing Social 
Sciences, 26(12): 14-16. (in Chinese)

Zhang J X, Zhang X L, Zhang W, 2002. On planning organization of rural settlement system. Human Geography, 17(1): 85-96. (in Chinese)

Zhang L, Du H R, Lei J Q et al., 2016. Influencing factors of reconstructing the rural residential areas in minority area in Hotan, Xinjiang. China Population, Resources and Environment, 26(6): 136-147. (in Chinese)

Zhang T, Liu Y X, Wang Y L, 2017. The rural spatial evolution and reconstruction on a resilience view. Acta Ecologica Sinica, 37(7): 2147-2155. (in Chinese)

Zhang X L, Sheng M, 2005. The reorientation of rural geography in China. Human Geography, 17(1): 81-84. (in Chinese)

Zhang Y T, Xiao Y Y, 2009. Influences of TOD (Transit Oriented Development) on scale and structure of Chinese residential areas. Huazhong Architecture, 27(6): 164-167. (in Chinese)

Zhao K, Hui Z J, 2008. Research of rural suitable farming radius in north Shanxi yellow soil inter-vale area. Shanxi Architecture, 34(8): 14-15. (in Chinese)

Zhao R, Wang E Y, Zhang X L et al., 2006. Human Geography. Beijing: Higher Education Press. (in Chinese)

Zhen W R, 2010. Evaluation and optimization of rural public service based on the farmers' satisfaction in Zhejiang. Agricultural Economy, 30(7): 15-17. (in Chinese)

Zheng H W, Gao J Z, Zang Y J et al., 2017. Analysis on farmers' satisfaction at rural ecological civilization construction. Bulletin of Soil and Water Conservation, 37(4): 52-57. (in Chinese)

Zhou G H, He Y H, Tang C L et al., 2013. Dynamic mechanism and present situation of rural settlement evolution in China. Journal of Geographical Sciences, 23(3): 513-524.

Zhou Q H, 2009. Loess Plateau. Settlements in the Valleys: Spatial Patterns of Human Settlements in Northern Shaanxi. Beijing: China Architecture \& Building Press. (in Chinese)

Zhou X Q, Zhang X L, 2005. Retrospect and expectation of rural geography in China. Economic Geography, 25(2): 285-288. (in Chinese)

Zhu X H, Chen Y F, Liu Y S et al., 2010. Technique and method of rural land consolidation potential investigation and assessment: A case study of Yucheng City, Shandong Province. Acta Geographica Sinica, 65(6): 736-744. (in Chinese)

Zhu X Q, Wang Z, Ying S A, 2010. The evolution and spatial adaptability of mixed-use settlements: Analysis on live-work unit under “Zhejiang pattern”. Economic Geography, 30(6): 933-937. (in Chinese)

Zhu X X, Zhu J G, Qiao J J, 2016. Research progress and Chinese rural settlement. Human Geography, 31(1): 33-41. (in Chinese)

Zhu Y L, Zhou L H, Huang Y B et al., 2009. The influential factors and regional differences of farmers' life satisfaction in the agro-pastoral ecotones of northern China: A case study in Yanchi County. Economic Geography, 29(2): 303-307, 279. (in Chinese) 